\title{
Digitalization of the Book Publishing Industry. A Study on the E-Book Publishing in Turkey
}

\author{
Şafak Erkayhan, Yeditepe University, Turkey \\ Yunus Bora Ülke, Yeditepe University, Turkey
}

\begin{abstract}
Developments in information and communication technologies have led to significant changes all over the world. With the digitalization process information has begun to turn from analogue to digital media, in the meantime global book publishing industry has taken steps from print publishing into electronic publishing. With the emergence of electronic book, book publishing sector started to gain a different meaning and has gained the characteristics of being a brand-new industry.

The aim of the research is giving support to improve e-book publishing sector in Turkey detecting current issues and providing information to create solutions. Making a detailed literature survey the research, firstly, investigates and compares the development of the ebook publishing industry in Turkey and in the world through the process of digitalization. And secondly, using qualitative and quantitative research methods it has been questioning the issues of the digitalization of the publishing sector in Turkey and conducting the preferences of the Turkish readers on e-books.
\end{abstract}

Keywords: Communication Technologies, Digitalization, E-book Publishing Industry, Turkey 


\section{Introduction}

With the widespread use of the Internet and establishment of faster and more versatile (interactive) communication medium has led to information and communication technologies develop further (Göker, 2009; Önder, 2010). With the development and widespread use of the Internet, e-books also have gained importance and books reach to readers over different mediums like web and e-book reader devices.

E-book, in simple terms a book which provides access to readers the contents of any book in electronic form (Hawkins, 2000). They are basically high-tech reading tablets that hold the equivalent of thousands of paper pages. You download text into them, and they display it on built-in screens (Robb, 1998).

E-books are new numeric book forms which are designed to be read with computers or portable e-book readers, and which provide new facilities in addition to having all the features of printed books but not being printed on papers. E-book consists of hardware and software. Assessing in this perspective, e-books associate with a specially designed portable hardware combination (Morgan, 1999; Rukancı and Anameriç, 2003).

As De Jong and Bus 2003 quoted it is a media format that contains audio, image, film, with interactive multimedia connections which can be read/watched in computers and specially designed hand tools. Electronic books show opportunities of discovery to find new ways in the interaction with information. Electronic books consist of many beneficial learning activities including reading, problem solving, and self-assessment (De Jong and Bus, 2003).

An e-book is the digital media equivalent of a conventional printed book. It is a special computer file which contains the text of a printed book which may be read on a personal computer (PC), a personal digital assistant (PDA) or an electronic device designed specifically for reading e-books (e-book reader). E-book readers have many features that are simply not available with standard printed text (Nikam and Rai, 2009). As Chrystal, 2010 emphasized it is an electronic or digital representation of a given text, whether scanned, typed, or programmed (for example, using HTML), having virtual "pages", that are read using e-book reading software, either on a personal computer, a PDA, a smart phone, or on a dedicated e-book reading device (Chrystal, 2010). 
Lin and Hubbard, 2000 remarked that there are several unique advantages their structure offers over printed publications. Many of these advantages are inherent in the format of the electronic devices; digital instruments can offer a level of features and flexibility that will never be possible through printed books (Lin and Hubbard, 2000).

Most of the advantages inherent in e-books are related to the technological differences between electronic publishing and traditional paper publishing. E-book technology makes things possible that could never be attempted on paper. The advantages of e-book publishing can be broken down into readability, usability, changeability, portability, multimedia capability, and availability (Stork, 2000; Mohan, 2001). With the increasing technological developments new advantages of e-books can be added such as producibility, utility, interactivity and sociability (Ülke, 2016: 59).

The most distinctive feature of e-books could be seen that it is an interactive medium. One way communication in the printed book turns into increasingly interactive communication in e-book and that provides readers a different experience in books.

Simple e-books which consist of simple text (non-interactive e-books) replaced later by compound e-books (reactive e-books) which consist of some visual and auditory media (image, video, audio, etc.) These stylistic changes have brought about significant changes in the interaction between readers and e-book. With e-books, with features such as combining of voice, video, and written communication and later 3D images and animations, virtual reality, voice recognition, and social network connection EPUB3 based Enhanced e-books a model of interactive e-books began to be created.

Enhanced e-books offer enhanced and interactive content, such as High-res, interactive images, animations, pop-up windows, maps, graphs, and charts, jump and push links, guided tours, slideshows, 3D renderings, video, and audio, audio narration, games, self-tests and adaptive learning functionality, social network connection (Biçer, 2006).

\section{Global E-Book Publishing Industry}

The market details of global media mediums - together with the cultural and educational publications - indicate how the book publishing industry is big and has an important place. 
Readers from around the world spend an estimated $€ 114$ billion on books per year. This amount includes not just print and digital editions of various kinds of trade books (like fiction, nonfiction and children's books), but also many sorts of educational materials, as well as professional and scientific publications. The consumption -and in many places: the availability - of books is far from even across the almost 200 countries worldwide. On the contrary, with a combined value of close to $€ 70$ billion, the six largest book markets - United States, China, Germany, Japan, France and Great Britain- together account for over $60 \%$ of the global spending on books (Wischenbart, 2013).

Because of its several significant advantages especially with the low cost, saving from time and space, being accessible at every moment e-books began to take more and more attention by publishers as well as readers in last years.

The fact that e-book market has grown steadily all over the world has been confirmed by published reports and statistical data. When the data of the book industry is analyzed especially in the first six of the biggest book industry in the world (US, Britain, Germany, France, Japan, China) it has been detected that it has a much larger ratio compared to other countries. Today, e-books constitute $21 \%$ of the total book market in the US. This ratio is approximately in Britain 17\%, in 10\% Germany, $7 \%$ in France, $10 \%$ in Japan and $10 \%$ in China.

Table 1. Global E-book Revenue from 2009 to 2016 by Region

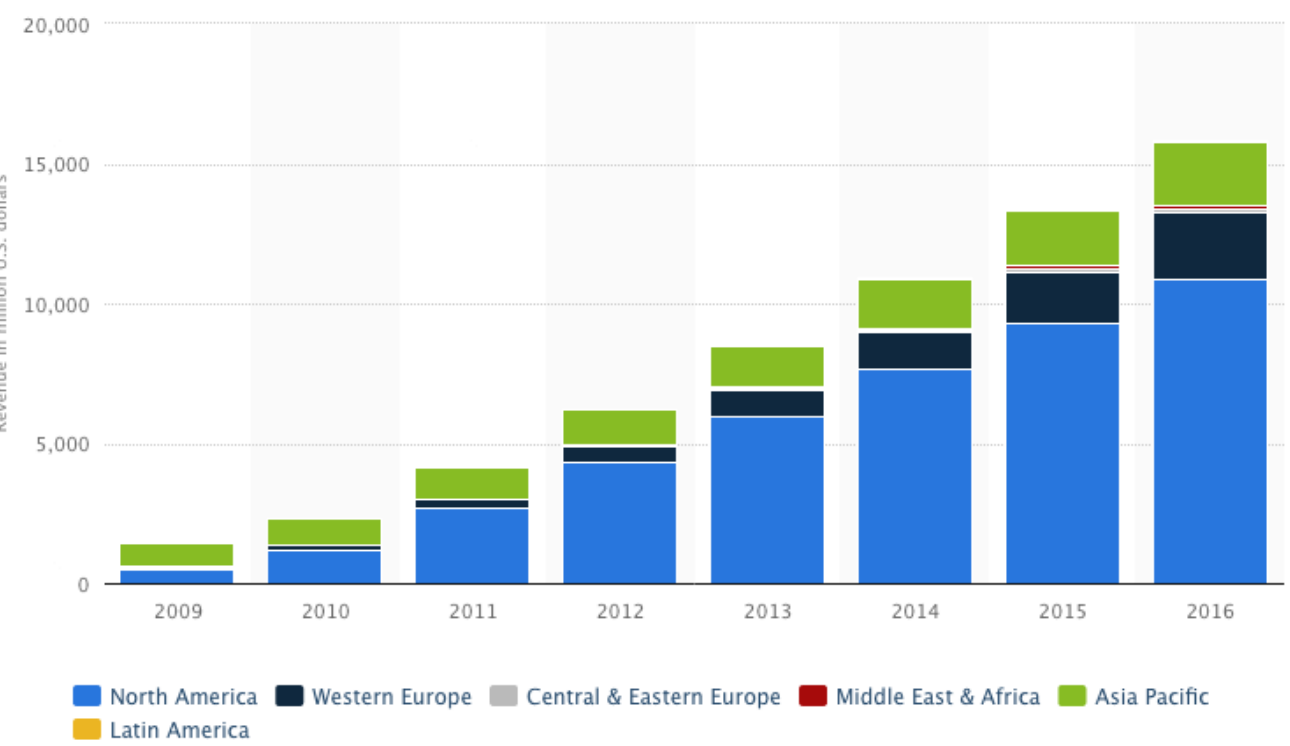


Electronic books have been around for over twenty years, but it was not until the recent mobile revolution that the medium's revenues began to reflect its potential. The North American market, boosted by surge of interest from consumers in the United States, is one of the fastest-growing e-book markets in the world, but growth in Western Europe and the Asia Pacific region is predicted to increase.

Between 2008 and 2012, the unit sales per year increased by over 400 million units, and by 2018, the e-book share of total book sales is expected to grow to over 25 percent, more than doubling its share from 2013. Whereas electronic book consumption and revenue is expected to grow, almost all print book categories are expected to decrease.

The data given above suggest that global e-books publishing is in a rapid growth and has an important share in global book market revenue, this growth is much more bigger especially in US, UK and Europe markets that has leading role the industry (Statista, 2014).

\section{The Turkish E-Book Publishing Industry}

With the entry of the computer in the 1990s, the Internet in the early 2000s smartphones after 2007, a significant increase in the use of information technologies has been recorded in Turkey as well as all over the world. According to the results of his research by GlobeScan for the BBC Four out of every five people in the world see Internet access as a fundamental human right. $87 \%$ of Internet users participating in the research have expressed their opinion as the Internet has to be accepted as a basic right for all people. The ratio of those who do not use the Internet was recorded as $70 \%$. In Turkey $90 \%$ of the population see Internet access as a fundamental human right and this ratio is said to be higher than the EU (Kazanc1, 2010). According to data from Household Information Technology Usage Survey of Turkey Statistical Institute (TSI) the computer usage rate for individuals in the 16-74 age groups is $53.5 \%$ and Internet usage rate is $53.8 \%$. These ratios are $62.7 \%$ and $63.5 \%$ respectively in men, it is $44.3 \%$ and $44.1 \%$ for women. 
Table 2. Household Information Technology Usage Survey of Turkey Research 2014 Basic Indicators (2007-2014)

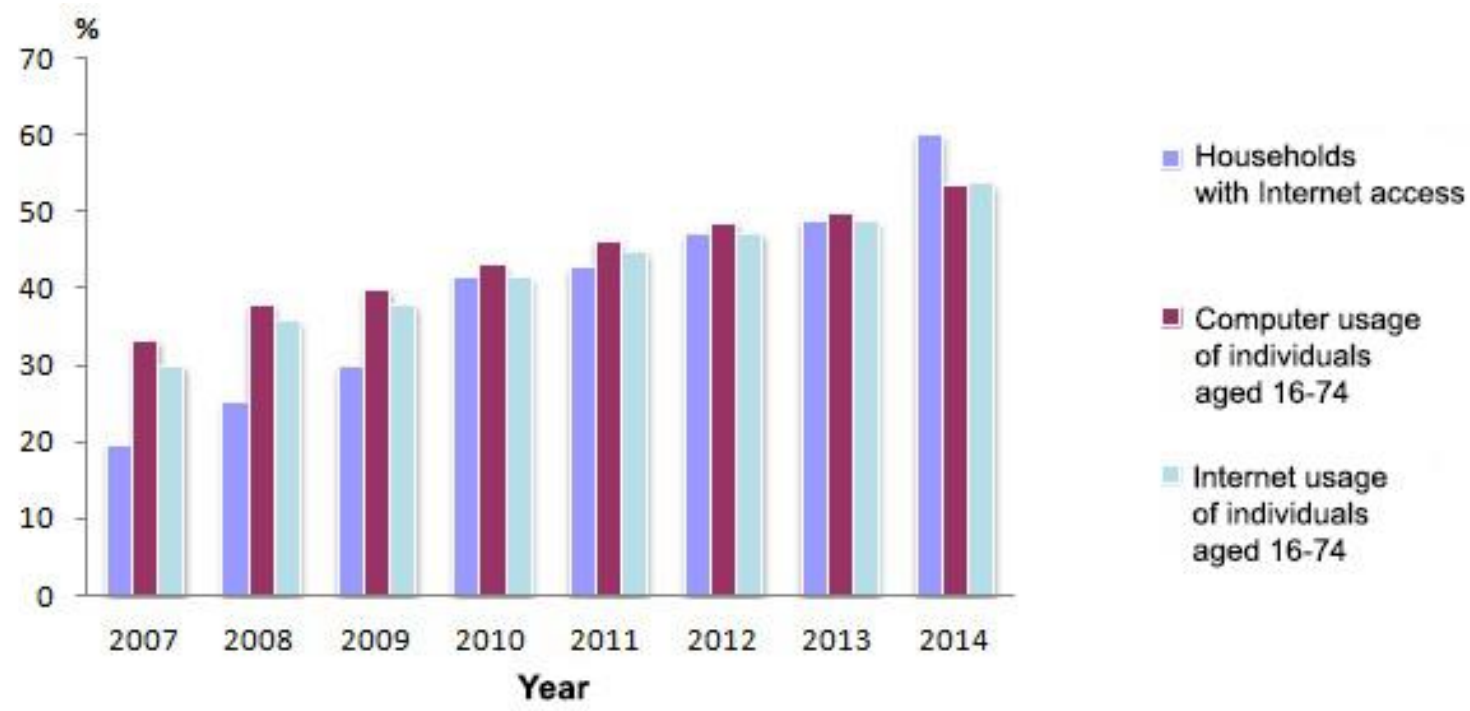

Research shows that computer and Internet usage rate is highest in the age group of 16-24. This confirms the predictions, that contact of the younger generation with information technology is much higher and this is the case in the future in connection with concept of Digital Natives/Digital Immigrants also mentioned in the previous subjects

Again according to the results of the same survey the proportion of households with Internet access in Turkey is $60.2 \%$ in April of $201442.8 \%$ of households do not have access to the Internet at home reported that they do not need on use the Internet.

$79.1 \%$ of 16-74 age groups of individuals who uses Internet the first three months of 2014 used it at home. This is followed by with $38.7 \%$ in the workplace, with $30.2 \%$ relatives' and friends' houses, with $23.3 \%$ shopping centers airports, and so on. Locations can be made wireless connectivity and Internet cafes with $14.3 \%$.

The use of portable devices for Internet usage outside houses and the workplaces has also increased. While \%58 of individuals who uses Internet outside houses and the workplaces in the first three months of 2014 used a mobile phone or smart phone to connect to the Internet wirelessly, $28.5 \%$ of them used portable computers (laptop, notebook, tablet, etc.) (TSI) 
Although the data introduces the improvement of digitalization process and increasing usage of information technologies in Turkey, Boyraz, 2006 transmitted that the Turkish book publishing market remains one of the smallest in comparison to the developed book markets in US and EU countries. The book publishing industries in these countries are highly and increasingly articulated within the spectrum of culture industries. The heavy foreign capital investments by major multinational media conglomerates at national level enforced the development of book publishing markets in these countries, through mergers, acquisitions, and joint-ownership. In general, it can be said that total volume of the book markets in developed book publishing markets remain much higher than the Turkish market (Boyraz, 2006).

Electronic publishing has started to gain importance in Turkey as well as all over the world when media organizations set up their own web site and move the newspapers and magazines to the Internet. In this sense the first examples are Aktïel magazine and Zaman newspaper which entered the publication on the Internet in 1995 (Keş, 2009). After this date, other newspapers and magazines started to be published on the Internet and to transfer existing traditional publications electronic mediums as well (Kazanc1, 2010).

E-books have published via several online publishing houses as free books and has presented to the readers. Later on by the support of state institutions Turkey's first e-book sales platform Idefix established and in the following years it followed by new sales platforms. Even all these developments had played a key role in the development of e-book publishing in Turkey, decisions, legal regulations taken especially in the national publication congress, projects support electronic publishing starting to create the technological infrastructure are the main reasons that led the way for the development.

Although electronic book publishing in Turkey is still insufficient compared to printed book publishing, when TSI's ISBN data of last five years is examined in detail, it is seen that ebook began to have an important place showing large increases each year in publishing. 
Table 3 ISBN Statistics 2008-2014 Number of Published Material Type

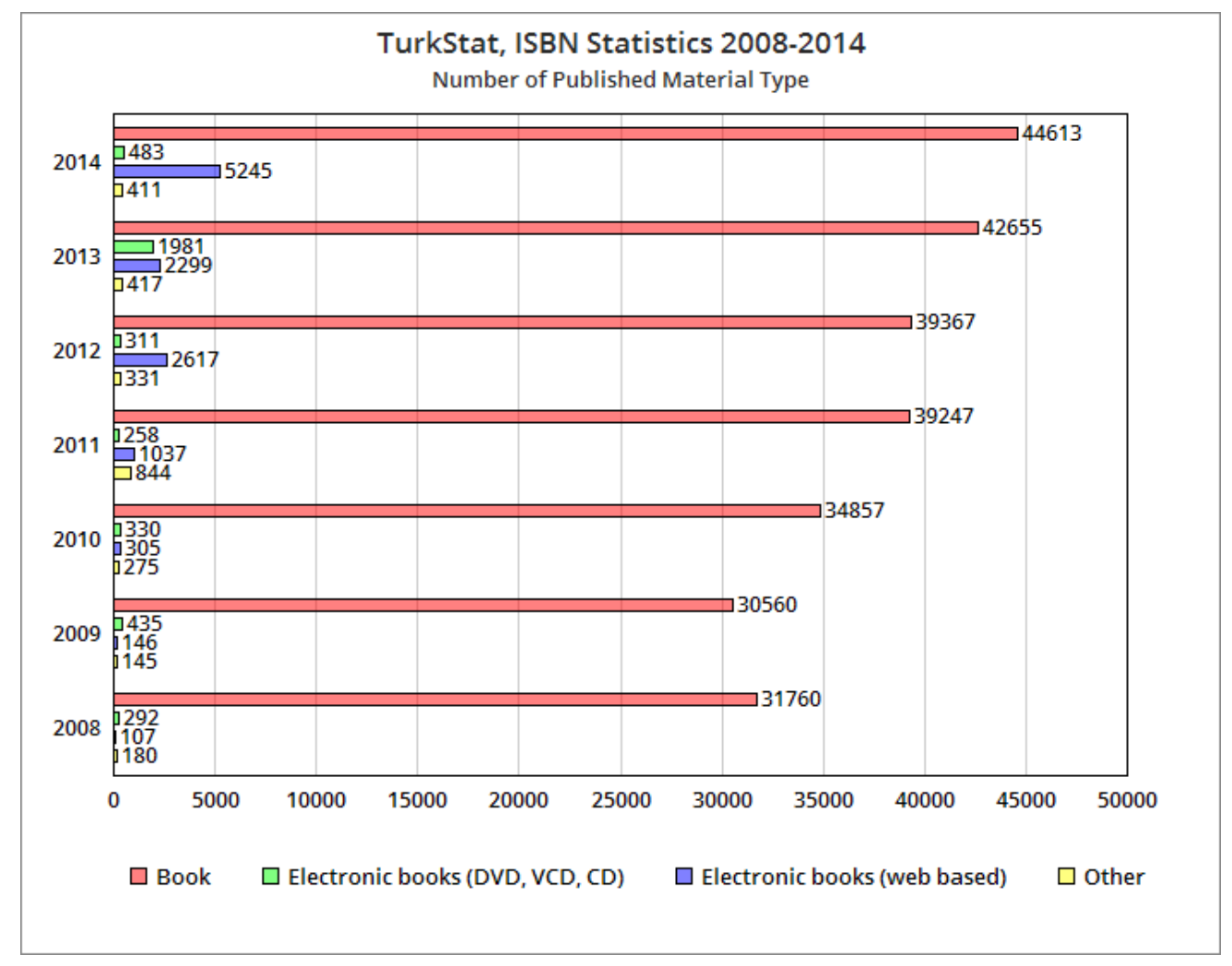

Table 3 indicates that the web-based electronic book publishing shows a large increase except for 2013. The most important reason is that is the increasing number published e-book and Interest in electronic books of the institutions in the private sector. For example, when we look at the number of published materials we can see that in 2014 , we can see that 44.613 books and 5.245 web-based electronic books have been produced. These data shows that one is an electronic book out of every 10 books, which it is currently not at a rate to be underestimated. When we take into account the research on the use of information technologies, we can see that electronic books would have a larger share in book market in Turkey in the coming years (TSI).

\section{Research Methodology}

The research questioned the current situation of the e-book publishing industry in Turkey in frame of information technologies during the digitalization process. First of all, making a detailed literature survey it detects the development of e-book publishing in the world and compares the data with Turkish case. 
Afterwards, the research focuses on the questions of the current issues, the obstacles and the reader preferences on the e-book publishing industry in Turkey using qualitative and quantitative research methodologies.

In-dept Interwievs with the Professionals from the Sector: in order to get comprehensive information of actual issues and future directions of the publishing industry in the country, anin-depth interview was realized with the professionals from the sector: Metin Celal Zeynioğlu who is the president of the Turkish Publishers Association, Münir Üstün who is the president of the Press and Publication Association and the owner of the Profil Yayinlar1 and Yunus Sönmez who is the owner of Pegasus Yayınları were interviewed and the provided data was analyzed (Ülke, 2016).

Online Questionnaire with the Readers: an online interactive questionnaire with 15 questions, which allowed participants also the possibility of commenting and adding their ideas about ebooks, were presented to the book readers in the online publishing and book related social media sites. A total of 665 people were participated to the survey to answer and comment on e-books and transmit their preferences on the issue. Collected data were analyzed and also a comparative analysis was conducted.

\section{Findings}

\section{Table 4. The Age of the Participants/Readers}

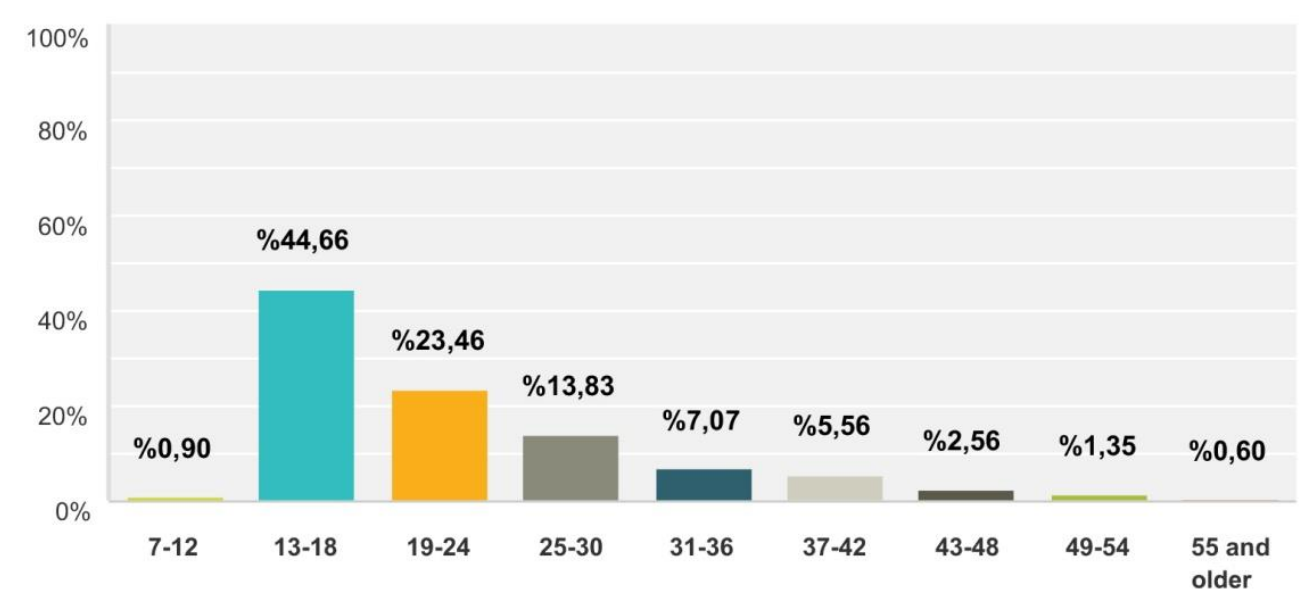

According to the demographic data provided from the questionnaire the highest number of the participants were the age group of " $13-18$ " with44.66\%. It is followed by the age group 
of "19-24" with $23.46 \%$ and "25-30" with $13.83 \%$. Minimum participation was held by the group of "55 and older" with $0.60 \%$. Another noteworthy point is that $79.40 \%$ of the participants is women. It is discovered that the younger generation with majority of women is more interested in e-books in Turkey. $73.98 \%$ of readers answer the question "Do you think you have enough information about e-book? as "Yes" and to the question "Where did you hear about e-book first?" with a large majority of $78.20 \%$ as "Internet". The answers reveal that readers have enough information about e-books and the information is mainly obtained via the Internet.

\section{Table 5. "Do you read e-book?"}

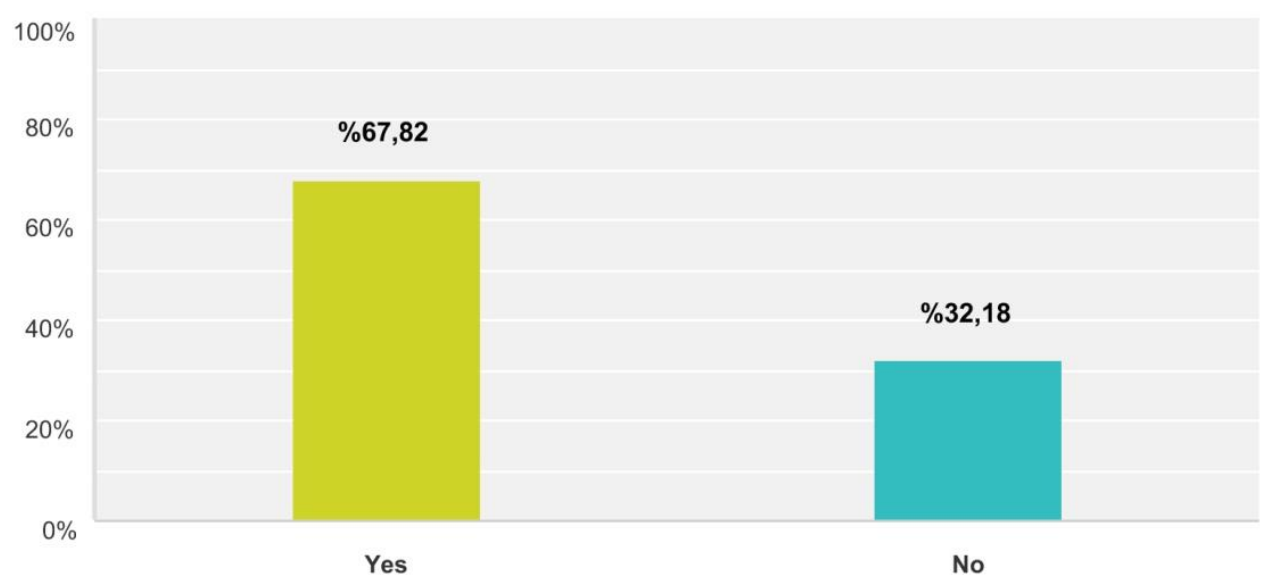

$67.82 \%$ of the participants answer the question "Do you read e-book?" as "Yes" and $32.18 \%$ as "No". And they answer the question respectively as "Always" with $10.23 \%$, as "Often" with $19.25 \%$, as "Occasionally" with $23.46 \%$, as "Rarely" with $20.90 \%$ and as "Never" with " $26.17 \%$. Provided data indicates that most of the participants are reading e-books and mostly occasionally. 


\section{Table 6. "Which Devices Do You Use to Read E-book ?"}

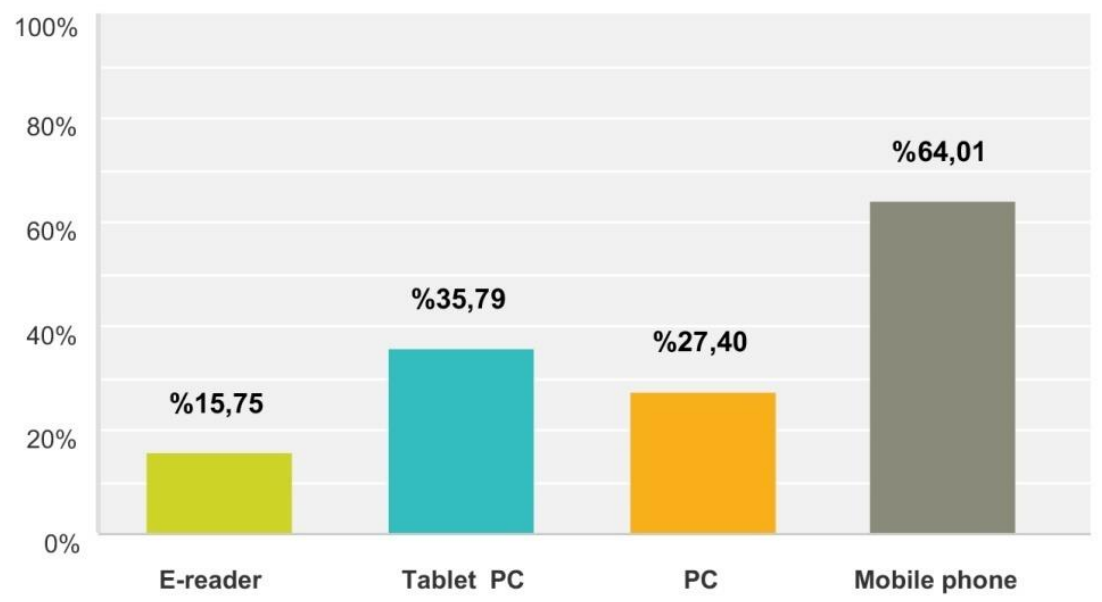

The readers transmitted that $64.01 \%$ of them use "Mobile Phone", 35.79\% "Tablet PC", 27.40\% "PC", and 15.75\% use "E-reader" as a device while they read e-book. The answers indicate that the number of participants who have reader device is relatively low and the most used device is mobile phone while they read e-book.

The readers were also questioned about their genre preferences. They answer the question "What genre do you prefer more when reading e-book?" as "Love/Romance" with $53.53 \%$, as "Fantasy/Science Fiction" with $48.76 \%$, as "Thriller/Crime" with $30.08 \%$, as "Literature" with $29.46 \%$, as "Academic" with $19.29 \%$, as "Non-Fiction" with $12.86 \%$ and as "Comics" with $10.58 \%$. The results show that the vast majority of e-book readers prefer to read Love/Romans and Fiction books. 
Table 7. "Which are the most Important Reasons for You to Prefer E-book?"

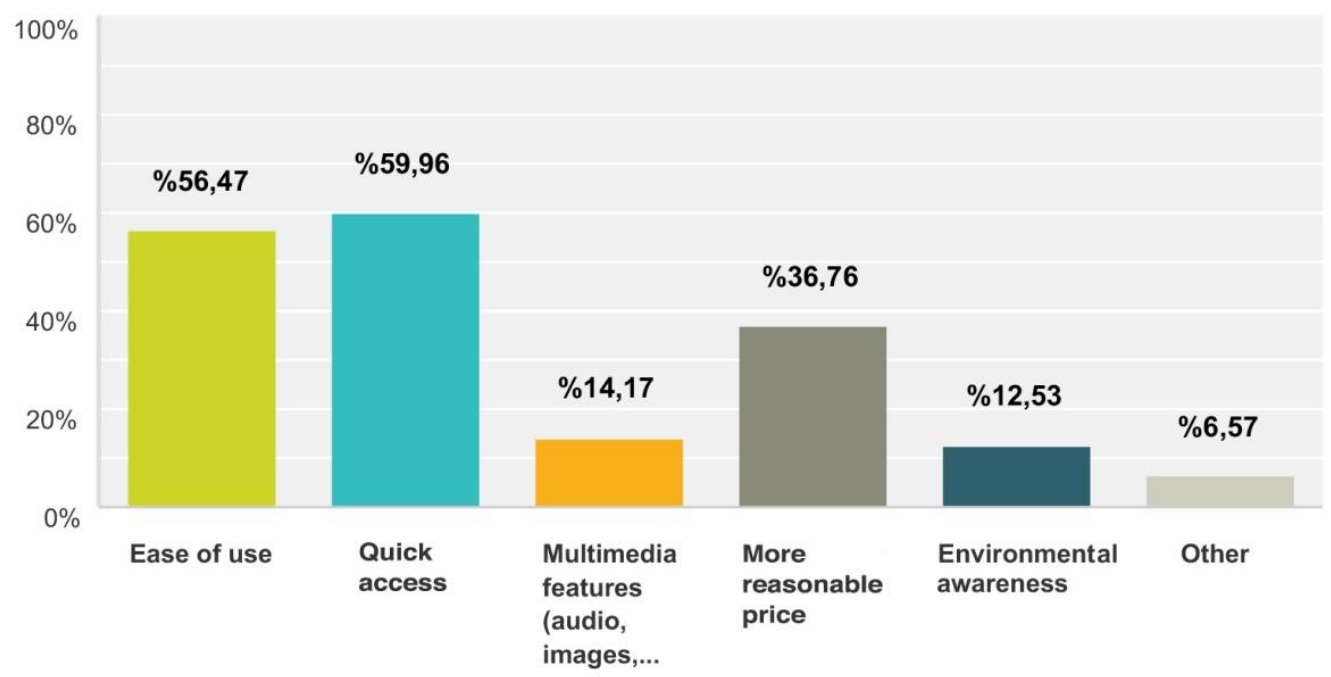

The participants prefer to read e-books because of "Quick Access" with 59.96\%, "Ease of Use" with 56.47\%, "More Reasonable Price" with 36.76\%, "Multimedia Features (audio, images, video, etc.)" with 14.17\%, "Environmental Awareness" with $12.53 \%$ and "Other" with $6.58 \%$.And also $32.03 \%$ of them find the usage of e-books "Very Easy", 30.83\% "Easy", 28.27\% "Normal", 6.32\% "Difficult", and 2.56\% "Very Difficult". According to the data the readers generally find e-book easy to use and they prefer to use it.

Table 8. “Are There Any Compelling Factors Reading E-book?"

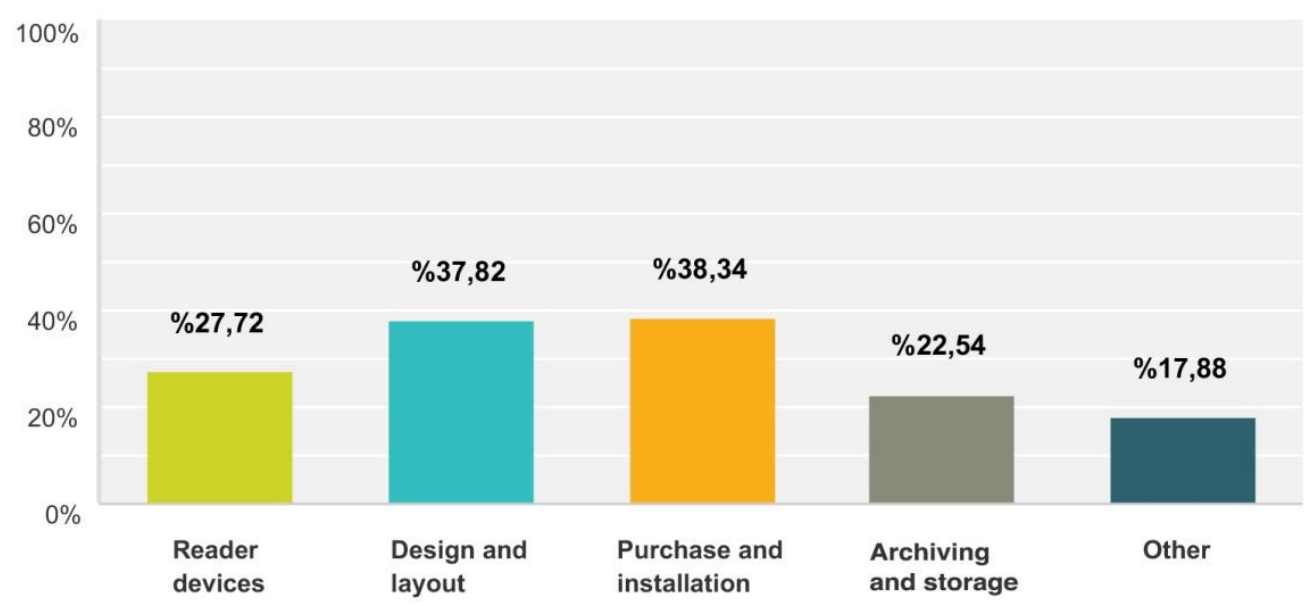

The question "Are there any compelling factors reading e-book?" is answered by the participants with $54.44 \%$ as "Yes". And these compelling factors are "Purchase and Installation" with 38.34\%, "Design and Layout" with 37.82\%, "Reader Devices" with 
$27.72 \%$, "Archiving and Storage" with $22.54 \%$ and "Other" with $17.88 \%$. Briefly, it can be said that main problems of the readers are caused by the technical infrastructure.

\section{Table 9. "What are the Issues that Prevent You to Purchase E-book in Turkey?"}

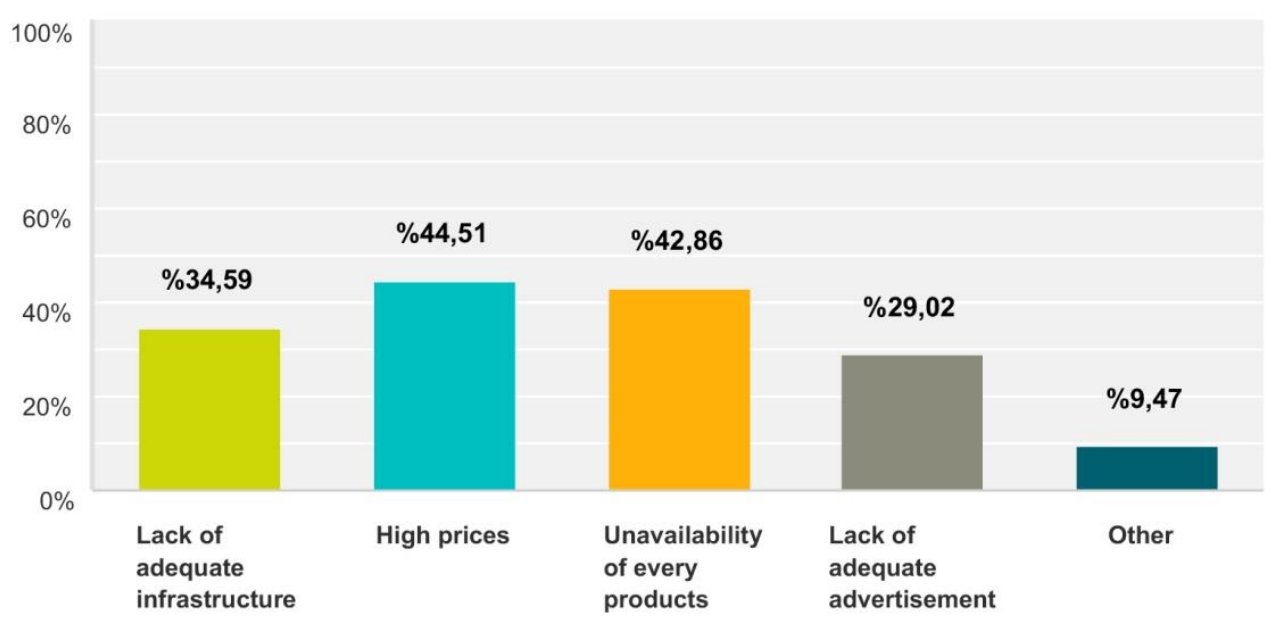

While the participants answer the question "Did you buy an e-book before?" as "No" with $61.35 \%$, they answered also the question "Did you buy a Turkish e-book before?" as"No" with $71.88 \%$.

The readers answer the question "What are the issues that prevent you to purchase e-book in Turkey?" as "High Prices" with $44.51 \%$, as "Unavailability of every products" with $42.86 \%$, as "Lack of adequate infrastructure" with $34.59 \%$, as "Lack of adequate advertisement" with $28.92 \%$, and as "Other" with $9.49 \%$.

Finally,the readers were asked to add their other comments on the subject. The vast majority of those who answered the question mentioned the high e-book prices and finding not every product they search in Turkey as a problem. Also this explains why they prefer to read pirated copy of e-books or free of charge sites like Wattpad.

\section{Conclusions}

The results of the literature survey emphasized that e-book market has grown steadily all over the world. When the data of the book industry is analyzed, it seems that especially the first six of the biggest book industry in the world has a much larger ratio compared to other countries. Today, e-books constitute $21 \%$ of the total book market in the US. This ratio is 
approximately $17 \%$ in Britain, $10 \%$ in Germany, $7 \%$ in France, $10 \%$ in Japan and $10 \%$ in China. Additionally, the statistical data implies general trend of increasing rates and shares of total revenue each year. In comparing to this trend of the world, it can be said that although some important steps have been taken on behalf of e-book publishing in Turkey, they were inadequate to increase the usage of e-books as the current rate of the e-book sales in Turkey is estimated about $4 \%$.

E-books have published via several online publishing houses as free books and has presented to the readers. Later on by the support of state institutions Turkey's first e-book sales platform Idefix established and in the following years it followed by new sales platforms. Even all these developments had played a key role in the development of e-book publishing in Turkey, decisions, legal regulations taken especially in the national publication congress, projects support electronic publishing starting to create the technological infrastructure are the main reasons that led the way for the development.

The research investigated the reasons of the underdevelopment in the e-book publishing industry in Turkey questioning the professionals of the sector as well as the Turkish readers. As the interviewed professionals from the publishing industry transmitted the main obstacles of the industry are the lack of technological infrastructure and the legal regulations; inefficiency of the state to improve related projects and organisations to support digital conversion; the lack of related institutions as well as actors with knowledge; disinvestment of the publishers; high prices; and the insufficiency of produced content. All these problems hinder the development and dissemination of e-book publishing in Turkey. The questionnaire answered by the 665 Turkish readers give also clues about the obstacles and preferences of e-book readers in Turkey as mentioned above.

The data provided by the online questionnaire indicated that vast majority of readers are interested in e-books. Especially, the younger generation at the age of "13-18" and "19-25" which is described as "Digital Natives" or "Generation Z", clearly has more attention to the digital content. As it is mentioned above the majority of the e-book readers are women The result of the research there has been detected six major issues that should be taken into account to develop Turkish e-book publishing industry: 
The first issue is the incompleteness technological infrastructure, absence of an e-book sales platform that serves for publishers with a transparent sales policy. All interviewed industry professionals have agreed the existence of an infrastructure problem in the country. Furthermore, according to online questionnaire the third important issue for the readers is "Lack of adequate infrastructure" with $34.59 \%$.Even though there are many e-book sales platforms in Turkey, none of these platforms provide satisfying services for publishers and readers. Today, there are three biggest e-book sales platforms in Turkey. These are: Idefix, D\&R and Babil. By reason of Babil is a newly established platform it is not sufficient in today's market position, but it brings a lot of innovation in e-book publishing compared to others.

Today, D\&R has the most e-book content in Turkey. With D\&R'spurchase of Idefix these two platforms come together under the umbrella of a single company and an e-book sales environment which later started to return to monopoly in the absence of competition has been created. In this environment, all control and authority system of e-book sales indexed to this platform and thus to a single company and it gives them opportunity to easily impose high commission rates and in unfair conditions to publishers. So a lot of publishers gradually begin to move away from e-book. Mr. Sönmez addresses to this situation in the interview in detail and as a solution and emphasizes the need to take e-book sales system abroad as a role model.

The solution to this problem is to examine technical infrastructure of e-book sales platforms abroad, in detail sales policies they implemented and DRM systems particularly in the US and UK. Except this, to bring an international e-book sales platform's (such as Amazon, $\mathrm{B} \& \mathrm{~N}$, etc.) sales system in Turkey, in case of making investments here this problem can completely be solved in a very quick period of time. The second major problem is the inadequacy of laws on the current e-book copyright. All industry professionals have also agreed that the current law is insufficient to improve electronic publishing.

The third important issue is state's inefficiency to organise the projects and investments to encourage e-book readers and publishers. The interviewed professionals mentioned "the Fatih Projects" which was not completed, would increase the interaction of younger generation called "Generation Z" or "Digital Natives", with digital content. As the research introduces 
the high interest of theyoung in e-book; implementation of related projects such as Fatih Project would provide the digital conversion in education actively.

The fourth major issue seems to be the high prices of e-books in Turkey. E-book pricesincluding the works of local authors seems little higher compared to international platforms. As Mr. Sönmez quoted the problem comes from high ratio of commissions demanded by the e-books sales platforms. If this commission rate is lowered a fair sales policy would be followed. An alternative solution would be creation of a digital library where users could have millions of content for a minimal fee such as Amazon's Kindle Unlimited.

Fifth major issue is the insufficiency of the number of e-book content in sales. Although the number of web-based e-book material in Turkey increases each year, it seems not in a satisfying level for readers. Even though e-book sales are made through more bestseller books all over the world, this is not the case in Turkey. The lack of technical infrastructure and non-transparent sales system are the main reasons. The sixth significant issue is lack of a leading institution or organization to inform and direct the actors (publishers, distributors, vendors, authors, etc.) of the sector. On this issue related institutions and organizations would come together to support and promote of development to e-book publishing and to improve policies.

The seventh major problems is the need for raising awareness on e-books using advertisements, videos, social media etc. The research introduces that E-book sale platforms or publishers in Turkey do not give enough importance to the promotion of e-books and there is a need for promotion to attract attention of readers especially via advertisements, videos, social media etc. 


\section{References}

Anameriç, H. and Rukanc1, F., 2003, "E-Book Technology and Its Use” Türk Kütüphaneciliği, 17(2): 147-166.

Biçer, S., 2006, Türkiye’de Internet Yayıncılığı Ve Avrupa Birliği’ne Uyum”, published Master Thesis, Gazi University, Ankara.

Boyraz, C., "Book Publishing In Turkey: Problems and Prospects in the Context of Industrialization”, published Master Thesis, The Middle East Technical University, Ankara, 2006.

Chrystal, R., 2010, “The Evolution of e-Books: Technology and Related Issues” Digital Libraries, 653.

De Jong, M.T., Bus, A.G., 2003, "How Well Suited Are Electronic Books To Supporting Literacy?", Journal of Early Childhood Literacy, 3: 147-164.

Göker, A., 2009, “Bilim ve Teknoloji Politikalarına Giriş İçin Enformasyon Toplumu Üzerine Kavramsal Bir Yaklaşım Denemesi”, Mülkiye Magazine, 25(230): 27-66. Hawkins, D.T., 2000, “Electronic Books - A Major Publishing Revolution. Part 1: General Considerations and Issues", Online, 24(4): 14-28.

Kazanc1, M., 2010, “Dijital Kitap (E-kitap) Yayıncılığı: Türkiye’deki Yayıncılık İçin Yeni Firsatlar, Eski Sorunlar”, published Expertise Thesis, Turkish Republic Culture and Tourism Ministry General Directorate of Libraries and Publications, Ankara.

Keş, Y., Elektronik Yayıncılık ve Web Tasarım, Hiperlink Yayınları, İstanbul, 2009. Lin X., and Hubbard J., 2000, “Books of the Future” Drexel University INFO 653:

Digital Libraries Final Paper. Available on site http://www.tk421.net/essays/ebooks.pdf

Mohan, H. R., 2001, “Web and Electronic Publishing Trends”, Paper: F, United States Educational Foundation in India.

Morgan, E. L., 1999, "Electronic Books and Related Technologies”, Computers in Libraries, 19(10): 36-39.

Nikam, K. and Rai, A. S., 2009, “Open E-books: The changing Paradigm” International Journal of Library and Information Science 1(1): 6-11.

Önder, I., 2010, “Elektronik Kitap Olgusu ve Türkiye'deki Durum”, published Master Thesis, Ankara University, Ankara.

Robb, J., 1998, “Are digital books good enough to curl up with?”. Available on site http://edition.cnn.com/TECH/computing/9810/09/digbooks.idg/ 
Stork, P. P., 2000, “The Promise of eBook Publishing”, The Internet Writing Journal, 1. Available on sitehttp://www.writerswrite.com/journal/oct00/the-promise-of-ebookpublishing-10007

Ülke, Y.B., 2016. Digitalization of the Book Publishing Industry: A Study on the E-Book Publishing in Turkey, Master Thesis, Yeditepe University, Institute of Social Sciences, İstanbul.

Wischenbart, R., 2013, “Global eBook - A report on market trends and developments”, Update fall 2013. 